\title{
Editorial: Chemically Mediated Interactions Between Marine Macrophytes and Microbes
}

\author{
Mahasweta Saha ${ }^{1 *}$, Elisa Berdalet ${ }^{2}$, Phillipe Potin ${ }^{3}$ and Bernardo A. P. Da Gama ${ }^{4}$ \\ ${ }^{1}$ Marine Ecology and Biodiversity, Plymouth Marine Laboratory, Plymouth, United Kingdom, ${ }^{2}$ Institut de Ciències del Mar \\ (CSIC), Passeig Marítim de la Barceloneta, Barcelona, Spain, ${ }^{3}$ CNRS, FR2424, Station Biologique de Roscoff, Sorbonne \\ Université, Roscoff, France, ${ }^{4}$ Departamento de Biologia Marinha, Universidade Federal Fluminense-UFF, Niterói, Brazil
}

Keywords: microalgae, macroalgae, seagrass, chemical ecology, infochemicals, microbes

\section{Editorial on the Research Topic}

\section{Chemically Mediated Interactions Between Marine Macrophytes and Microbes}

\section{OPEN ACCESS}

Edited and reviewed by: Angel Borja,

Technological Center Expert in Marine and Food Innovation (AZTI), Spain

*Correspondence:

Mahasweta Saha

sahamahasweta@gmail.com

Specialty section: This article was submitted to

Marine Ecosystem Ecology, a section of the journal

Frontiers in Marine Science

Received: 11 December 2020 Accepted: 21 December 2020

Published: 28 January 2021

Citation:

Saha M, Berdalet E, Potin P and Da Gama BAP (2021) Editorial:

Chemically Mediated Interactions Between Marine Macrophytes and Microbes. Front. Mar. Sci. 7:640494.

doi: 10.3389/fmars.2020.640494
Is it well-accepted that communication among organisms including land plants and aquatic macrophytes in terrestrial and aquatic ecosystems is largely achieved using information-conveying chemicals or "infochemicals" (Saha et al., 2019) which should be seen as a chemical "language" of life. Marine macrophytes and phytoplankton are dominant primary producers in marine ecosystems worldwide (e.g., Behrenfeld et al., 2001). They produce oxygen and form the base of food webs, are ecosystem engineers, and provide ecologically and economically valuable functions and services (e.g., Holdt and Kraan, 2011; Sarker et al., 2020; review by Pierella Karlusich et al., 2020). Phytoplankton and macrophytes are not single isolated entities but establish intimate relationships between them as well as with non-photosynthetic microbes (including bacteria, fungi, viruses) forming holobionts. These interactions in turn influence carbon and nutrient cycling, regulate the productivity and dynamics of aquatic food webs, and affect ocean-atmosphere fluxes of climatically relevant gases like dimethylsulphide and greenhouse gases like halocarbons. Associations and interactions between photosynthetic and non-photosynthetic organisms are chemically-mediated and are dependent on "cross-talk" infochemicals as well. However, our knowledge on the chemical "language of life" in aquatic ecosystems is still incipient (when compared to terrestrial environment). We do not know which infochemicals facilitate or inhibit the preferential attachment of macrophytes by microbes senso lato (i.e., including photosynthetic microalgae and cyanobacteria and heterotrophic bacteria), whether the selected macroalgae can stimulate the production of particular phycotoxins, whether microbes produce compounds (and if so, which chemicals) that act as deterrent of macrophytes grazing. Given the important role that the rapidly undergoing climate-driven changes (rising temperature, acidification, hypoxia, desalination) are playing in the aquatic ecosystems, potential modifications on such chemically mediated interactions (Schmidt and Saha, 2020) cannot be discarded. Identifying infochemicals and understanding their role have been challenging mainly by technical limitation. However, the emergence of cutting edge technical advances in the fields of analytical chemistry, cell biology, and the "omics" resources offer nowadays the possibilities to achieve rapid progress into the field of chemically mediated algae-microbe interactions under the present oceans. This Research Topic ensembles seven research articles and one review paper aimed at advancing our knowledge of the chemically mediated macroalgae - microalgae-microbe interactions.

A plethora of commercial and environmental applications may rise from a better understanding of the interactions among marine macroalgae (seaweeds) and associated microbes. For example, Burgunter-Delamare et al. conducted an exhaustive characterization of the genomes-sequencing 
of 10 bacteria associated to the model brown alga Ecotocarpus siliculosus. Also, the genome-based reconstruction of their metabolic networks was conducted. The potential metabolic activities were then compared with metabolites produced by the macroalga. This allowed to predict which bacteria could facilitate the growth of the macroalgae. From the most promising consortia, some preliminary co-culture experiments were conducted testing the exchange of selected chemicals between alga and bacteria suggesting beneficial metabolites exchanges in the holobiont.

Califano et al. investigated to what extent Integrated Multi-trophic Aquaculture (IMTA) influences the microbiome associated with the commercially important green alga Ulva rigida, comparing diversity, and taxonomic composition of wild vs. IMTA-grown algae and surrounding water. Amplicon Sequence Variants (ASVs) revealed that prokaryotic richness was higher in aquaculture water than on wild samples, and in both cases, richness was also higher in water than on Ulva samples. Aquaculture thus promoted the presence of known morphogenesis-inducing bacteria, suggesting that IMTA may shape the microbial community of cultured Ulva, including previously undetected taxa with unknown traits. This knowledge can facilitate the establishment of sustainable and environmentally friendly aquaculture.

On the other hand, a better understanding on how marine macroalgae deter undesired epibiotic growth may lead to the development of new, environmentally safer antifouling paints (Da Gama et al., 2014; Saha et al., 2017). Bioassayguided fractionation of glycolipids from the brown seaweed Sargassum vulgare led to the isolation of three sub-fractions that demonstrated promising antifouling activity toward marine bacteria and microalgae (Plouguerné et al.). The main compounds in these fractions are monogalactosyldiacylglycerols (MGDG), digalactosyldiacylglycerols (DGDG), and sulfoquinovosyldiacylglycerols (SQDG). These compounds appear to mediate microbial colonization of this macrophyte. Following this line, Ternon et al. characterized the surface metabolome and explored the bioactivity of surface extracts of four macroalgae, Dictyota dichotoma, Dictyota spiralis, Taonia atomaria, and Padina pavonica, that are common substrates of microalgae, including the toxic dinoflagellate Ostreopsis cf. ovata. Laboratory experiments combined with the analysis of the eukaryotic diversity (using 18S rRNA gene metabarcoding) of the organisms attached to the macroalgae in situ indicated that $D$. dichotoma could be the most bioactive macroalga, causing negative physiological responses on $O$. cf. ovata. However, the proliferation of $O$. cf. ovata depends on complex and multiple ecological factors. In fact, the blooms of this microalga may constitute a paradigm of the chemical ecology, due to the wide diversity of chemically driven responses exhibited by other microand macroorganisms exposed to Ostreopsis proliferations, as comprehensively reviewed by Pavaux et al. Ostreopsis produces toxins and attaches to the substrates (macroalgae, rocks, sand) by secreted mucopolysaccharides. These biomolecules may be involved in allelopathy and competitive interactions with the microbiota and predators' deterrence leading to
Ostreopsis blooms and also involved in the negative impacts on human health and certain benthic macrofauna. However, innovative tools and realistic experiments are needed to understand the dynamics and ecotoxicity of the Ostreopsis blooms and other benthic toxic dinoflagellates. With this objective, Tarazona-Janampa et al. using molecular and chemical tools characterized a wide range of bacterial assemblages associated to Prorocentrum lima species complex. In this case, the complex experiments conducted did not provide evidence that allelopathic interactions among the toxic microalgae and bacteria could play a definable role in the growth and toxin production by $P$. lima species complex. The results suggest that other internal physiological processes or environmental factors can modulate the toxicity of this microalgal blooms.

A wide range of microbes, from bacteria to fungi, also colonize the internal tissues of macroalgae. However, chemically mediated interactions of macroalgae with these endosymbiotic microbes remain poorly explored to date and were addressed by Vallet et al. Novel $\alpha$-hydroxy- $\gamma$-butenolides isolated from the obligate marine fungus Paradendryphiella salina were found to interfere with bacterial quorum sensing. Comparative metabolomics revealed the presence of $\alpha$-hydroxy- $\gamma$-butenolides among all the $P$. salina strains isolated from different hosts. Also, a high metabolic variability related to the alga-host species was found, highlighting the key role of microbial chemical communication that may occur within the tissue of the macroalgal holobiont. Along with marine macro- and microalgae, seagrasses are also known to engage in chemically mediated interactions with surface associated microbes (Guan et al., 2017). Such defense can be dynamic in nature and has been recently shown to fluctuate at a seasonal scale (Guan et al., 2019). However, how such defense and the responsible infochemicals may respond to climate change induced stressors like marine heatwaves is not known yet. To answer this, Guan et al. demonstrate how climate change imposed stressors like marine heatwaves may alter the infochemicals produced by the seagrass Zostera marina in the Western Baltic. In a mesocosm study where the authors simulated near natural heatwaves, the capacity to deter microbial colonizers was to be significantly up-regulated in Z. marina from heatwave treatments (with one or three heatwaves) in comparison to $Z$. marina under control conditions, suggesting defense regulation of $Z$. marina in response to marine heatwaves.

\section{PERSPECTIVES}

Shedding light upon the nature of chemically mediated interactions between marine macrophytes and microbes (sensu lato) may lead not only to a better understanding of their ecology, susceptibility to environmental changes, but also to a number of applications, such as improved and safer aquaculture, biofouling prevention, and bioinvasion mitigation. Furthermore, a better understanding of the chemical interactions within the microbiota is necessary to improve the comprehension of the factors leading to the occurrence and toxicity of 
harmful algal blooms, and probably, to prevent their negative impacts on human health and other marine organisms. This collection has also brought together research aimed at understanding chemically mediated interactions of marine macrophytes under current and future ocean conditions, investigating infochemicals from both seaweeds and seagrasses and how certain infochemicals may behave under climate change scenarios like marine heatwaves. In doing so, this Research Topic supports a framework for disseminating new, transdisciplinary knowledge providing an unprecedented opportunity to understand the role of chemical signaling in structuring algae-microbes interactions and its possible large-scale impact on ocean health and uses.

\section{AUTHOR CONTRIBUTIONS}

MS conceived the idea, designed, and planned the research topic, invited other co-editors, and wrote the

\section{REFERENCES}

Behrenfeld, M. J., Randerson, J. T., McClain, C. R., Feldman, G. C., Los, S. O., Tucker, C. J., et al. (2001). Biospheric primary production during an ENSO transition. Science 291, 2594-2597. doi: 10.1126/science. 1055071

Da Gama, B. A. P., Plouguerné, E., and Pereira, R. C. (2014). The antifouling defence mechanisms of marine macroalgae. Adv. Bot. Res. 71, 413-440. doi: 10.1016/B978-0-12-408062-1.00 014-7

Guan, C., Saha, M., and Weinberger, F. (2019). Chemical defence of a seagrass against microfoulers and its seasonal dynamics. Applied Sciences 9:1258. doi: 10.3390/app9061258

Guan, C. D., Parrot, J., Wiese, F. D., Sönnichsen, M., Saha, D., and Tasdemir, and Weinberger, F. (2017). "Identification of rosmarinic acid and sulfated flavonoids as inhibitors of microfouling on the surface of eelgrass Zostera marina." Biofouling 33, 867-880. doi: 10.1080/08927014.2017.1 383399

Holdt, S. L., and Kraan, S. (2011). Bioactive compounds in seaweed: functional food applications and legislation. J. Appl. Phycol. 23, 543-597. doi: $10.1007 /$ s10811-010-9632-5

Pierella Karlusich, J. J., Ibarbalz, F. M., and Bowler, C. (2020). Exploration of marine phytoplankton: from their historical appreciation to the omics era. J. Plankton Res. 42, 1-18. doi: 10.1093/plankton/ fbaa049 manuscript. EB and $\mathrm{BD}$ contributed substantially to the editing and writing. PP contributed to the editing. All authors contributed to the article and approved the submitted version.

\section{FUNDING}

EB acknowledges CoCliME (which is part of ERA4CS, an ERA-NET initiated by JPI Climate, and funded by EPA (IE), ANR (FR), BMBF (DE), UEFISCDI (RO), RCN (NO), and FORMAS (SE), with co-funding by the European, Union; Grant Number 6904462). BD acknowledges CNPq for a Research Productivity grant.

\section{ACKNOWLEDGMENTS}

MS acknowledges Plymouth Marine Laboratory for a PML fellowship.

Saha, M., Berdalet, E., Carotenuto, Y., Fink, P., Harder, T., John, U., et al. (2019) Using chemical language to shape future marine health. Front. Ecol. Environ. 17, 530-537. doi: 10.1002/fee. 2113

Saha, M., Goecke, F., and Bhadury, P. (2017). Minireview: algal natural compounds and extracts as antifoulants. J. Appl. Phycol. 30, 1859-1874. doi: 10.1007/s10811-017-1322-0

Sarker, P. K., Kapuscinski, A. R., McKuin, B., Fitzgerald, D. S., Nash, H. M., and Greenwood, C. (2020). Microalgae-blend tilapia feed eliminates fishmeal and fish oil, improves growth, and is cost viable. Sci. Rep. 10:19328. doi: 10.1038/s41598-020-75298-x

Schmidt, R., and Saha, M. (2020). Infochemicals in terrestrial plants and seaweed holobionts: current and future trends. N. Phytol. doi: 10.1111/nph.16957. [Epub ahead of print].

Conflict of Interest: The authors declare that the research was conducted in the absence of any commercial or financial relationships that could be construed as a potential conflict of interest.

Copyright (C) 2021 Saha, Berdalet, Potin and Da Gama. This is an open-access article distributed under the terms of the Creative Commons Attribution License (CC BY). The use, distribution or reproduction in other forums is permitted, provided the original author(s) and the copyright owner(s) are credited and that the original publication in this journal is cited, in accordance with accepted academic practice. No use, distribution or reproduction is permitted which does not comply with these terms. 